\title{
Monocyte superoxide anion production in rheumatoid arthritis: preliminary evidence for enhanced rates of superoxide anion production by monocytes from patients receiving penicillamine, sodium aurothiomalate and corticosteroids
}

\author{
N.P. HURST, B. BESSAC, AND G. NUKI \\ From the Rheumatic Diseases Unit, Department of Medicine (WGH), University of Edinburgh, Northern \\ General Hospital, Edinburgh EH5 $2 D Q$
}

SUMMARY In-vitro studies of superoxide $\left(\mathrm{O}_{2}^{-}\right)$anion production by blood monocytes after stimulation with either serum treated zymosan (STZ), IgG treated zymosan (IgGTZ), or fluoride ion $\left(\mathrm{F}^{-}\right)$ were performed on cells from normal controls $(n=22)$ and patients with classical or definite rheumatoid arthritis (RA) $(n=35)$. Twenty-two of the patients were on nonsteroidal antiinflammatory drugs (NSAID) alone and 13 were on either sodium aurothiomalate, penicillamine, corticosteroids, or a combination. Monocytes from RA patients on 'second-line therapy' showed significantly increased rates of $\mathrm{O}_{2}^{-}$release in response to STZ compared with normal controls, but no increase was seen in monocytes from patients on NSAID alone. With IgGTZ as the stimulus, rates of $\mathrm{O}_{2}^{-}$release were increased in monocytes from patients on NSAID alone compared with normal controls $(p<0.02)$, but were increased to a greater extent in monocytes from patients on second-line therapy $(\mathrm{p}<0.01)$. There were no differences in basal unstimulated $\mathrm{O}_{2}^{-}$production and no differences after stimulation with $\mathrm{F}^{-}$. The enhanced release of $\mathrm{O}_{2}^{-}$by monocytes from patients on second-line therapy could not be attributed to increased disease activity and may be an effect of therapy.

Mononuclear phagocytes, which include tissue macrophages and their precursors, blood monocytes, are thought to play an important role in chronic inflammation. Rheumatoid synovium contains numerous mononuclear phagocytes ${ }^{1}$ which are a potential source of a variety of secretory products, including neutral proteases, lysosomal acid hydrolases, prostaglandins, leukotrienes, complement components, and oxygen-free radicals. ${ }^{2}$ Oxygen-free radicals, which include superoxide anion $\left(\mathrm{O}_{2}^{-}\right)$, hydroxyl radical $(\mathrm{OH})$, and singlet oxygen $\left({ }^{1} \mathrm{O}_{2}\right)$, make an important contribution not only to host defence against infection ${ }^{3}$ and tumour cells ${ }^{45}$ but also against the tissue damage which may accompany inflammatory and immunological processes. ${ }^{26-8}$ Furthermore, in RA there is biochemical evidence of free radical mediated oxidative damage, which includes reduced

Accepted for publication 4 February 1983.

Correspondence to Dr N. P. Hurst, Rheumatic Diseases Unit, Northern General Hospital, Ferry Road, Edinburgh EH5 2DQ. availability of serum-free thiol groups, reduced levels of superoxide dismutase in erythrocytes, ${ }^{9}$ and the presence of free radical oxidation products of lipids. ${ }^{10}$ In-vitro studies have also emphasised the potential role of oxygen-free radicals in damage to connective tissue constituents, including hyaluronic acid ${ }^{11}$ and collagen. ${ }^{12}$

Phagocytosis of immune complexes by mononuclear phagocytes is a potential stimulus to oxygen-free radical release in RA, but the phagocytic event is not a necessary prerequisite for free radical generation, and the processes are functionally distinct. ${ }^{1314}$ Various soluble stimuli, including $\mathrm{C} 5 \mathrm{a},{ }^{14}{ }^{15}$ can activate oxygen-free radical release, while others, including lymphokines ${ }^{16}$ and proteases, ${ }^{17}{ }^{18}$ can enhance or 'prime' the free radical responses of phagocytes.

The capacity of mononuclear phagocytes from patients with RA to generate oxygen-free radicals has not been widely studied, and as part of an investigation of the role of the mononuclear phagocyte in 
RA we have compared $\mathrm{O}_{2}^{-}$production by blood monocytes from normal controls and patients with classical or definite RA.

\section{Materials and methods}

Subjects. Twenty-two healthy hospital and laboratory employees ( 11 male, 11 female; mean age $40 \cdot 2 \pm$ (SD) 13.3 years and 35 patients with classical or definite RA were studied. ${ }^{19}$ Twenty-two of these patients were taking NSAID alone $(n=21)$ or no antirhe umatic therapy $(n=1)$ (11 male, 11 female; mean age $51 \cdot 4 \pm 16.6$ years), and 13 patients ( 7 male, 6 female; mean age 50.9 \pm 12.9 years) were taking either sodium aurothiomalate $(n=3)$ (total dose $0.6-1.05 \mathrm{~g})$, penicillamine $(\mathrm{n}=4)(125-500 \mathrm{mg}$ per day), corticosteroids $(n=4)(2 \cdot 5-10 \mathrm{mg}$ prednisolone per day or 8-10 units ACTH per day), or a combination $(n=2)$ for at least 3 months. Eleven of the 13 patients receiving 'second-line therapy' (includes patients receiving corticosteroid therapy) were receiving NSAID in addition.

Assessment of $R A$ disease activity. A composite score (0 to 6) to indicate increasing disease activity was assigned to each patient. The score was based on erythrocyte sedimentation rate (ESR, $\mathrm{mm} / 1$ st hour), early morning stiffness (EMS), and a subjective global assessment with 3 categories-inactive, moderately active, and very active disease. Scores of 0 , +1 , and +2 were given for $\operatorname{ESR}<26,26$ to 50 , and $>50$; EMS $<1$ hour, 1 to 2 hours, $>2$ hours; and inactive, moderately active, and very active disease respectively.

\section{MONOCYTE SEPARATION}

Indicator-free Hanks's balanced salt solution (HBSS) with 5 units $/ \mathrm{ml}$ preservative-free heparin was used throughout.

Venous blood from each subject was anticoagulated with $10 \mathrm{mM}$ EDTA. Mononuclear cells (lymphocytes and monocytes) were separated from blood according to the method of Boyum ${ }^{20}$ on a density gradient (Lymphoprep, Nyegaard, Oslo). The mononuclear cell fraction was washed twice in HBSS and resuspended to give a final monocyte concentration of between 0.60 and $1 \cdot 20 \times 10^{9} / 1$. Exact concentrations of monocytes and lymphocytes in the final suspension were determined with a ZBI Coulter counter with a $70 \mu \mathrm{m}$ aperture as previously described. ${ }^{21}$ This method of counting numbers of monocytes and lymphocytes was validated by comparison with nonspecific esterase stains of cytocentrifuge preparations of mononuclear cells. ${ }^{22}$ Control studies with naphthol AS-D chloroacetate esterase staining of mononuclear cells showed only insignificant contamination by neutrophil polymorphs in both normal controls and RA patients (mean $0 \cdot 4 \%$, range $0-4 \%$ ).

CONTROL STUDIES ON LYMPHOCYTES

Since lymphocytes are present in large numbers in mononuclear cell preparations obtained from density gradients, control studies were carried out on enriched lymphocyte fractions to determine their contribution, if any, to $\mathrm{O}_{2}^{-}$production. Lymphocytes were purified by removal of adherent cells (monocytes), and $\mathrm{O}_{2}^{-}$generation was assayed as described below.

\section{PREPARATION OF STIMULI}

Zymosan was preopsonised in bulk as follows:

(i) $C 3 b / I g G$ coated zymosan (STZ). Zymosan was incubated with fresh human serum obtained from a single donor in a ratio of $10 \mathrm{mg}$ zymosan/ml serum.

(ii) IgG coated Zymosan (IgTZ). Zymosan was incubated in pooled human IgG (Blood Transfusion Service, Edinburgh) in a ratio of $10 \mathrm{mg}$ zymosan/75 $\mathrm{mg} \mathrm{IgG} / \mathrm{ml}$ phosphate buffered saline (PBS).

Opsonisation was carried out at $37^{\circ} \mathrm{C}$ for 30 minutes, the zymosan washed 3 times with PBS and resuspended to $25 \mathrm{mg}$ of zymosan/ml of PBS. After opsonisation the zymosan was stored in $0.25 \mathrm{ml}$ aliquots in liquid nitrogen. Direct immunofluorescence staining of STZ showed the presence of $\operatorname{IgG}, \lg M$, and $\mathrm{C} 3 \mathrm{~b}$, while IgGTZ showed the presence of IgG alone. Sodium fluoride $(\mathrm{NaF})^{23}$ was dissolved in PBS to give a $200 \mathrm{mM}$ solution, with appropriate reduction of sodium chloride concentration to maintain isotonicity, and adjusted to $\mathrm{pH} 7 \cdot 3$.

ASSAY OF SUPEROXIDE ANION PRODUCTION Superoxide anion $\left(\mathrm{O}_{2}^{-}\right)$was measured by the reduction of horse heart ferricytochrome (type III Sigma) as previously described.$^{24}$ All experiments were performed in duplicate in plastic tubes $(9 \times 11 \mathrm{~mm}, \mathrm{RT}$ 25 , Sterilin). Aliquots $(400 \mu \mathrm{l})$ of cell suspension were mixed with $50 \mu$ l cytochrome c in PBS $(100 \mu \mathrm{M}$ final) and $50 \mu \mathrm{l}$ of the appropriate stimulus. Control tubes containing bovine superoxide dismutase (SOD) (type I, Sigma) at a final concentration of 200 $\mu \mathrm{g} / \mathrm{ml}$ were included in each experiment. The tubes were capped and incubated at $37^{\circ} \mathrm{C}$ on a turntable for 60 minutes. The reaction was terminated by placing the tubes in iced water for 10 minutes and then spinning at $1000 \mathrm{~g}$ for 10 minutes. The extent of cytochrome reduction in the supernatant was measured as the change in absorbance at $550 \mathrm{~nm}$ after the addition of a grain of potassium ferricyanide, in a Cecil spectrometer using an extinction coefficient of $21 \cdot 1 \mathrm{mM}^{-1}$ $\mathrm{cm}^{-1} \cdot{ }^{25}$ The total amount of cytochrome $\mathrm{c}$ present was obtained from the absorbance at $550 \mathrm{~nm}$ after the further addition of a few grains of sodium dithionite. 
Control studies confirmed that for a given stimulus the reduction of cytochrome $c$ followed first-order kinetics over 60 minutes and that the rate was directly proportional to the monocyte concentration. A rate constant $\mathrm{K}$ for reduction of cytochrome $\mathrm{c}$ by $\mathrm{O}_{2}^{-}$could thus be obtained from the expression:

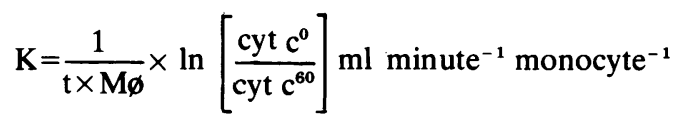

where $\mathrm{t}=$ time (minutes), $\mathbf{M} \emptyset=$ monocyte concentration, and cyt $\mathrm{c}^{0}$ and cyt $\mathrm{c}^{60}$ are the concentrations of oxidised cytochrome c initially and after 60 minutes incubation respectively. Rates of reduction of cytochrome c by $\mathrm{O}_{2}^{-}$are expressed in terms of this rate constant.

Any cytochrome $\mathrm{c}$ reduction occurring in the presence of SOD was assumed to be due to reducing agents other than $\mathrm{O}_{2}^{-}$, and these results are shown separately. In addition to the superoxide dismutase controls 2 additional tubes were always included, to which $50 \mu$ l PBS were added in place of stimulus. This provided a measure of basal $\mathrm{O}_{2}^{-}$production by monocytes.

Statistical methods. Student's $t$ test was used to make statistical comparisons.

\section{Results}

CONTROL STUDIES ON LYMPHOCYTES

Incubation of a lymphocyte-enriched cell preparation confirmed that lymphocytes make no significant contribution to $\mathrm{O}_{2}^{-}$production. The rate of production of $\mathrm{O}_{2}^{-}$was $1.5 \mathrm{nmoles}$ of reduced cytochrome $\mathrm{c}$ per $10^{6}$ lymphocytes per hour. This is equivalent to a rate constant of $0 \cdot 26 \times 10^{-9} \mathrm{ml} / \mathrm{minute} /$ lymphocyte and is probably due to the small numbers of contaminating monocytes in the lymphocyte-rich preparation.

\section{PATIENT STUDIES}

Basal superoxide anion production and SOD controls There was no significant difference in mean $( \pm \mathrm{SD})$ basal unstimulated rates of monocyte $\mathrm{O}_{2}^{-}$ production between normal controls $(1 \cdot 28 \pm 0 \cdot 45$ $\mathrm{ml} / \mathrm{min} /$ monocyte), RA patients receiving NSAID alone $(1.45 \pm 0.33 \mathrm{ml} / \mathrm{min} /$ monocyte $)$, and RA patients on second-line therapy $(1 \cdot 33 \pm 0.26$ $\mathrm{ml} / \mathrm{min} /$ monocyte).

Similarly, in the SOD controls there was no significant difference in mean $( \pm S D)$ 'non-dismutase inhibitable' cytochrome $\mathrm{c}$ reduction between normal controls $(1.07 \pm 0.39 \mathrm{ml} / \mathrm{min} /$ monocyte $), \quad \mathrm{RA}$ patients receiving NSAID alone $(1 \cdot 13 \pm 0 \cdot 28$ $\mathrm{ml} / \mathrm{min} /$ monocyte), and patients on second-line therapy $(1 \cdot 06 \pm 0.24 \mathrm{ml} / \mathrm{min} /$ monocyte $)$.

\section{Stimulated superoxide anion production}

In the presence of fluoride ion a 6-fold increase in rates of $\mathrm{O}_{2}^{-}$production over basal levels occurred, but there were no differences between any of the groups studied (Fig. 1).

With $\mathrm{IgTZ}$, rates of $\mathrm{O}_{2}^{-}$production were significantly increased in monocytes from RA patients on 'second-line therapy' $(p<0 \cdot 01)$ and to a lesser extent in monocytes from RA patients on NSAID alone $(p<0.02)$ compared with normal controls (Fig. 1).

With STZ significant enhancement of $\mathrm{O}_{2}^{-}$generation was seen in monocytes from patients on secondline therapy $(p<0 \cdot 001)$ compared with normal con-

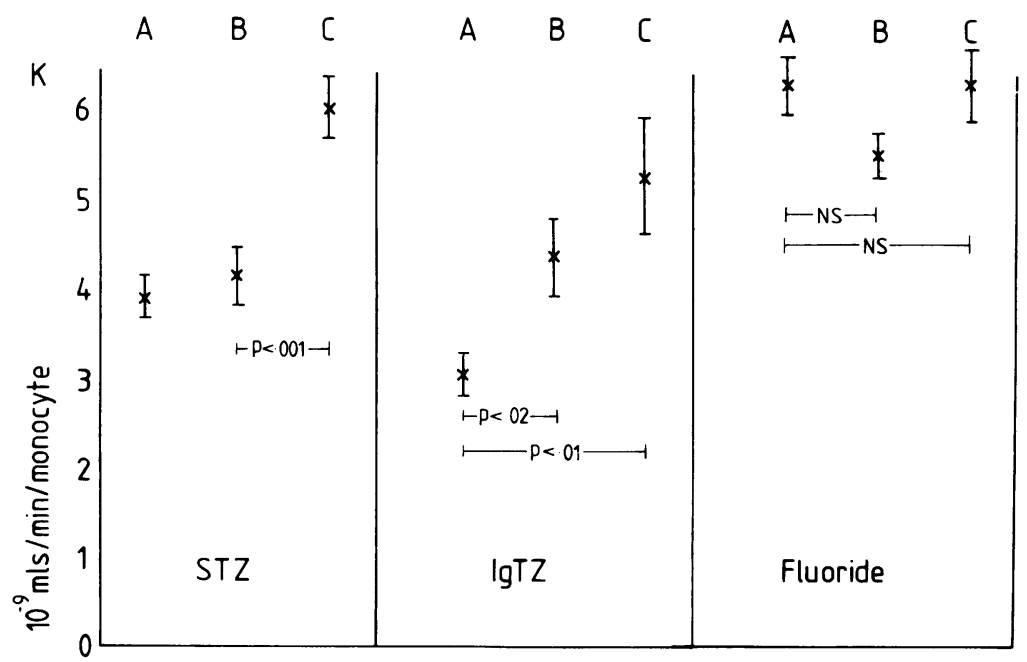

Fig. 1 Rate constant $K$ for cytochrome c reduction by $\mathrm{O}_{2}^{-}$. Mean $( \pm S E M)$ superoxide release after fluoride $\left(F^{-}\right), S T Z$, or $I g T Z$ stimulation of monocytes from group A normal controls $(n=22)$, group B $R A$ patients on NSAID only $(n=22)$, and group C $R A$ patients on second-line therapy $(n=12)$. 


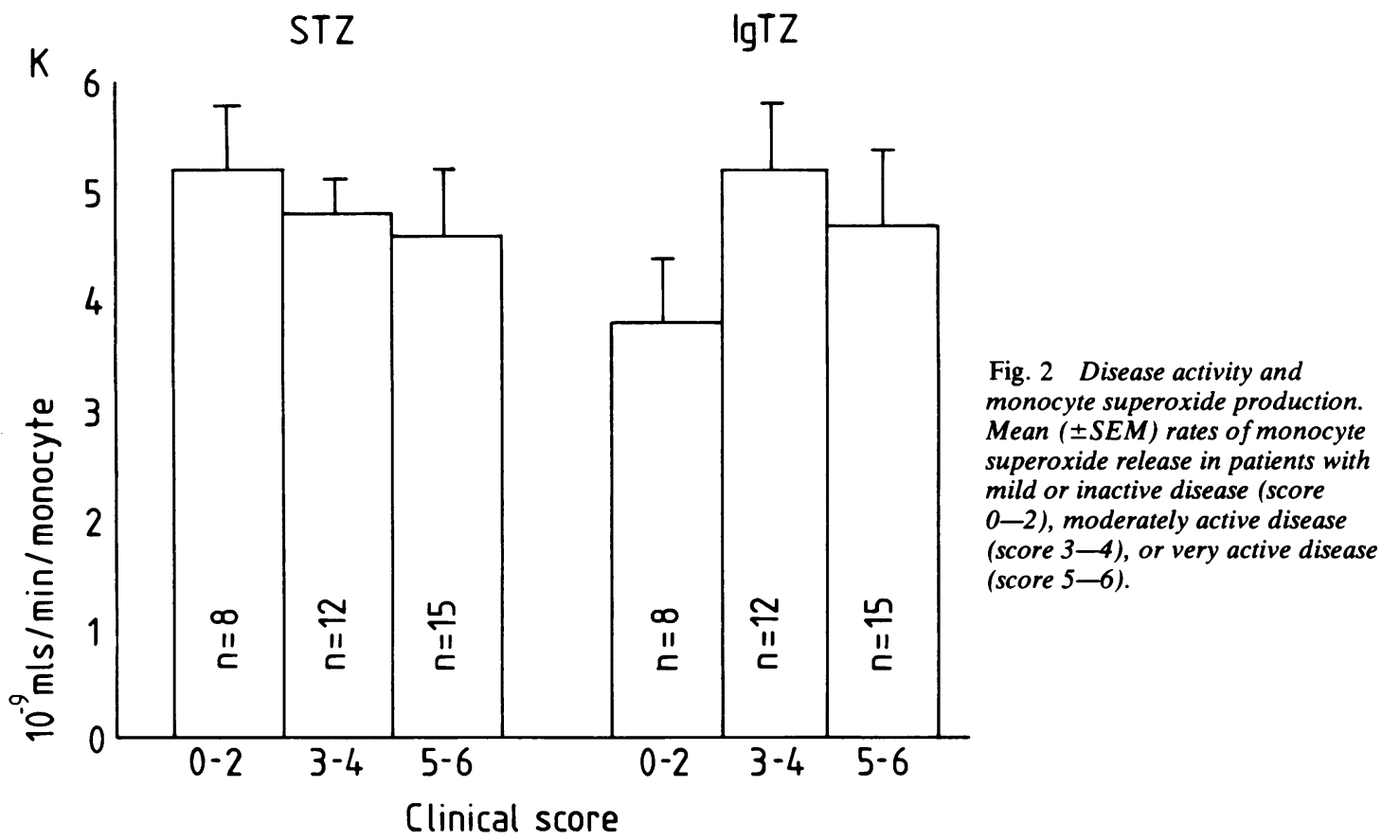

trols, but no enhancement was seen in monocytes from patients on NSAID alone (Fig. 1).

Correlation of in vitro rates of $\mathrm{O}_{2}^{-}$production with disease activity

No significant differences in monocyte $\mathrm{O}_{2}^{-}$production were found between patients with mild or inactive disease, moderately active disease, or very active disease (Fig. 2). Furthermore, although patients or second-line therapy had higher rates of in-vitro monocyte $\mathrm{O}_{2}^{-}$production, they had a lower mean clinical score $(2 \cdot 9 \pm 2 \cdot 5)$ than those on NSAID alone $(4 \cdot 3 \pm 1 \cdot 7)$. These differences are not statistically significant.

As there was no significant difference in mean values for superoxide production in patients under treatment with gold, penicillamine, or corticosteroid drugs, the results have been analysed as a combined 'second-line therapy' group in each case.

\section{Discussion}

These results suggest that monocytes from some RA patients have enhanced capacity to generate $\mathrm{O}_{2}^{-}$in response to immunological stimuli but not to a soluble biochemical stimulus such as fluoride ion. An increase in rates of $\mathrm{O}_{2}^{-}$release was found primarily with monocytes from patients on second-line therapy and was more marked after stimulation with STZ, a combined $\mathrm{C} 3 \mathrm{~b} / \mathrm{Fc}$ receptor stimulus, than with $\mathrm{IgTZ}$, which stimulates Fc receptors alone. No comparable increase in basal unstimulated release of $\mathrm{O}_{2}^{-}$was seen, suggesting that these differences were not due to immune complexes binding to monocyte receptors and causing prior stimulation. Furthermore, the differences were entirely attributable to enhanced $\mathrm{O}_{2}^{-}$ release, since there was no change in levels of 'nondismutase inhibitable' reducing activity.

Enhanced extracellular release of $\mathrm{H}_{2} \mathrm{O}_{2}$ and $\mathrm{O}_{2}^{-}$by mononuclear phagocytes is seen both after stimulation in vitro with lymphokines and after antigenic stimulation in vivo with BCG or Corynebacterium parvum. ${ }^{1626}$ It has been suggested that such augmentation of oxidative metabolism is a feature of mononuclear phagocyte activation, ${ }^{26}$ and it is therefore of considerable interest that this phenomenon should be identified in monocytes from patients with RA.

In our patients a number of factors might be responsible for enhancement of $\mathrm{O}_{2}^{-}$release and include disease activity, an effect of second-line therapy or conceivably loss of inhibition of $\mathrm{O}_{2}^{-}$production after reduction of NSAID intake by patients on second-line therapy. Mechanisms by which this could occur include changes in monocyte receptor expression, enhancement of intracellular NADPH production, or, by reduction of NSAID intake, removal of potential inhibitors of $\mathrm{O}_{2}^{-}$production. ${ }^{15}$ On the basis of the data presented and preliminary 
data from a prospective study of patients before and after beginning second-line therapy ${ }^{27}$ the most likely cause of monocyte activation in these patients is the introduction of second-line therapy. Our data do not suggest that enhanced $\mathrm{O}_{2}^{-}$release is secondary to disease activity or to withdrawal of NSAID.

Altered receptor expression seems the most likely mechanism for the effect, since differences in $\mathrm{O}_{2}^{-}$ release were seen with opsonised zymosan but not with $\mathrm{F}^{-}$, a biochemical stimulus. The observations of previous workers using rosetting techniques on monocytes from RA patients who found enhanced Fc receptor expression, ${ }^{28}{ }^{29}$ and others ${ }^{30}$ who found increased antibody dependent cellular cytotoxicity (ADCC), lend support to this view. Furthermore, since ADCC may be mediated by oxygen free radicals, ${ }^{31}$ our data provide a biochemical mechanism for such an increase in functional activity. The in-vivo effects of penicillamine and sodium aurothiomalate on monocyte receptor expression in RA do not appear to have been studied, so direct enhancement of receptor expression by these drugs cannot be excluded. On the other hand there is evidence that sodium aurothiomalate and penicillamine raise intracellular levels of glutathione and SOD,$^{32}$ and this might secondarily increase levels of NADPH, the key substrate for $\mathrm{O}_{2}^{-}$production. Since we cannot preclude the possibility that stimulation with $\mathrm{F}^{-}$was too insensitive to detect differences in rates of $\mathrm{O}_{2}^{-}$generation, a biochemical rather than an immunological mechanism could also account for enhancement of $\mathrm{O}_{2}^{-}$production.

In conclusion, our data provide evidence to suggest that monocytes from some RA patients have enhanced potential to generate oxygen-free radicals, but this should not be interpreted as evidence of increased release of $\mathrm{O}_{2}^{-}$in vivo. The association of this phenomenon with second-line therapy may provide further insight into the mode of action of these drugs and suggests that they may cause monocyte activation. To explore this possibility further we have undertaken a prospective study of $\mathrm{O}_{2}^{-}$production by monocytes from RA patients commencing secondline therapy.

The work was supported by grants from the Arthritis and Rheumatism Council.

\section{References}

1 van Furth $R$. The origin of phagocytic cells in the joint and bone. Scand J Rheumatol 1981; suppl 48: 13-20.

2 Nathan C F, Murray H K, Cohn Z A. The macrophage as an effector cell. $N$ Engl $J$ Med 1980; 303: 622-6.

3 Babior $B$ M. Oxygen dependent microbial killing by phagocytes (part 1 and part 2). N Engl J Med 1978; 298: $659-68,721-5$.

4 Clark R A, Klebanoff S J. Studies on the mechanism of antibody dependent polymorphonuclear leucocyte mediated cytotoxicity. J Immunol, 1977; 119: 1413-8.

5 Hafeman D G, Lucas Z J. Polymorphonuclear leucocyte mediated antibody dependent cellular cytotoxicity against tumor cells: dependence on oxygen and the respiratory burst. $J$ Immunol 1979; 123: 53-63.

6 Greenwald, R A. Oxygen radicals and connective tissue. $J$ Rheumatol 1981; 8: 185-7.

7 Abramson S, Hoffstein S T, Weissman G. Superoxide generation by human neutrophils exposed to monosodium urate. Arthritis Rheum 1982; 25: 174-80.

8 McCormick J R, Harkis M M, Johnson K J, Ward P J. Suppression by superoxide dismutase of immune complex induced pulmonary alveolitis and dermal inflammation. Am J Pathol 1981; 102: 55-61.

9 Banford, J C, Brown D H, Hazelton R A, McNeil C J, Sturrock R D, Smith W E. Serum copper and erythrocyte superoxide dismutase in rheumatoid arthritis. Ann Rheum Dis 1982; 41: 458-62.

10 Lunec J, Halloran S P, White R G, Dormandy T L. Free radical oxidation (peroxidation) products in serum and synovial fluid in rheumatoid arthritis. J Rheumatol 1981; 8: 233-45.

11 McCord, J M. Free radicals and inflammation: protection of synovial fluid by superoxide dismutase. Science 1974; 185: 529-31.

12 Greenwald R, Moy W W. Inhibition of collagen gelation by action of the superoxide radical. Arthritis Rheum 1979; 22: 251-9.

13 Johnston R B, Lehmeyer J E, Guthrie L A. Generation of superoxide anion and chemiluminescence by human monocytes during phagocytosis and on contact with surface bound immunoglobulin G.J Exp Med 1976; 143: 1551-6.

14 Goldstein I M, Roos D, Kaplan H B, Weissman G. Complement and immunoglobulins stimulate superoxide production by human leucocytes independently of phagocytosis. J Clin Invest 1976; 56: 1155-63.

15 Simchowitz L, Mehta J, Spilberg I. Chemotactic factor induced generation of superoxide radicals of human neutrophils. Arthritis Rheum 1979; 22: 755-63.

16 Walker L, Lowrie D B. Killing of Mycobacterium microti by immunologically activated macrophages. Nature 1981; 293: 69-78.

17 Johnstone R B Jr, Chadwick D R, Cohn Z A. Priming of macrophages for enhanced oxidative metabolism by exposure to proteolytic enzymes. J Exp Med 1981; 153: 1678-83.

18 Kitagawa S, Takaku F, Sakamoto S. Evidence that proteases are involved in superoxide production by human polymorphonuclear leucocytes and monocytes. J Clin Invest 1980; 65: 74-81.

19 Ropes M M, Bennet G A, Cobb S, Jacox R, Jessar R A. 1958 Revision of diagnostic criteria for rheumatoid arthritis. Arthritis Rheum 1959; 2: 16-28.

20 Boyum A. Isolation of mononuclear cells and granulocytes from human blood. Scand J Clin Lab Invest 1968; 21 (suppl 97): 77-89.

21 Loos H, Blok-Schut B, Kipp B, van Doors R, Meerhof L. Size distribution, electronic recognition and counting of human blood monocytes. Blood 1976; 48: 743-53.

22 Yam L T, Li C Y, Crosby W H. Cytochemical identification of monocytes and granulocytes. Am J Clin Pathol 1971: 55: 283-90.

23 Curnutte J T, Babior B M, Karnovsky M L. Fluoride mediated activation of the respiratory burst in human neutrophils. J Clin Invest 1979; 63: 637-47.

24 Weening R S, Wever R, Roos D. Quantitative aspects of the production of superoxide radicals by phagocytosing human granulocytes. J Lab Clin Med 1975; 85: 245-52.

25 van Gelder B F, Slater E C. The extinction coefficient of cytochrome C. Biochim Biophys Acta 1962; 58: 593-5.

26 Murray H K, Cohn Z A. Macrophage oxygen dependent antimicrobial activity III. Enhanced oxidative metabolism as an 
expression of macrophage activation. $J$ Exp Med 1980; 152: 1596-609.

27 Hurst N P, Bessac B, Nuki G. Heberden Society, Cambridge. Ann Rheum Dis 1982; 41: 632 (abstr.).

28 Hoch S, Schur P H. Monocyte receptor function in patients with rheumatoid arthritis. Arthritis Rheum 1981; 24: 1268-77.

29 Kavai M, Lukacs K, Sonkoly L, Paloczi K, Szegedi G. Circulating immune complexes and monocyte $\mathrm{Fc}$ function in autoimmune diseases. Ann Rheum Dis 1979; 38: 79-83.
30 Waytz P H, Douglas S D. Increased antibody dependent cell mediated cytotoxicity by monocytes from patients with rhe umatoid arthritis. Arthritis Rheum 1975; 22: 490-4.

31 Borregaard N, Kragballe $\mathrm{K}$. Role of oxygen in antibody dependent cytotoxicity mediated by monocytes and neutrophils.J Clin Invest 1980; 66: 676-83.

32 Munthe E, Kass E, Jellum E. D-penicillamine induced increase in intracellular glutathione correlating to clinical response in rheumatoid arthritis.J Rheumatol 1981; 8 (suppl. 7): 14-9.

\section{Book review}

CBE Style Manual. 5th edn. Pp. 326. US\$24.00. Council of Biology Editors, 9650 Rockville Pike, Bethesda, Maryland 20814, USA. 1983.

Success in medicine depends much on communicating through the written word. For those wishing to get ahead there is thus a strong case for adopting a professional approach to authorship. Facility in writing varies greatly, but, while practice is a great improver, there are also many publications offering helpful advice. What then should stand on the desk of the medical author and, for that matter, the editor, referee, and publisher? For those with the leisure to savour their reading and writing, volumes such as Fowler, Roget, and the Shorter OED will need to be supplemented with tables of SI units and microbial terminology. For others with less time to spare the increasingly comprehensive instructions to authors offered by some journals provides much useful advice. There remains, however, a need for a concise reference book dealing with all aspects of medical writing. This is admirably filled by the new edition of the CBE Style Manual.

The manual deals with writing in all the biological sciences, but most of it is relevant to medicine. It offers sound advice about the ethical aspects of authorship and publication; preparation of manuscripts, tables, and illustrations; prose style, including a list of common errors; technical style conventions; indexing; proof correction; refereeing ('Test the critique for fairness and objectivity by asking yourself if you would be willing to sign it and send it to the author'). The style of the manual itself is North American, but throughout it draws attention to differences between British and American usage, and these comparisons make interesting reading. The authors might have commented on how the simpler North American spelling avoids that most common error in British medical writing, the insertion of an inappropriate diphthong (as in thrombocytopaenia for thrombocytopenia). All in all, this is an excellent publication: concise, yet comprehensive and entertaining. I recommend it.

H. L. F. CURREY 